\title{
Perceived Leadership Traits of Employees Based on Physical Attributes and Social Desirability: an Indian Perspective
}

\author{
Shraddha Kulkarni
}

\begin{abstract}
The general perception about the importance of physical attributes and social desirability at the work place is very high. It has been considered as one of the major aspects for leadership traits. The purpose of this paper was to find the significance of physical appearance and social desirability in creating a positive impression at workplace. This study also tried to find out if these two attributes add to the perceived leadership capabilities of employees. In the present research, the author used a mix of qualitative \& quantitative research methods. In the first stage, a structured interview has been conducted for 90 managers from multinational firms and they have been asked about their perception on team members' physical appearance and social skills. In the second stage, a questionnaire survey has been conducted for 270 managers from banking sector. It has been observed that in both phases of research the respondents found the confidence, relevant work knowledge, communication skills and qualification more appealing as compare to dressing style and appearance and leadership traits are not directly related to the physical attributes and social desirability. However, the research also indicates that dressing style and grooming helps in creating positive impression and the acceptability of the leadership is easier in case of people with better physical \& social aspects. This research will provide a useful insight to the practitioners and $H R$ professionals to highlight the importance of communication skills, social skills, confidence for developing leadership traits amongst the employees. It will also help in communicating the importance of physical attributes such as dressing sense, body language, etiquettes etc.
\end{abstract} traits

Keywords: Physical attributes, social desirability, leadership

\section{INTRODUCTION}

In In the competitive era where the employee performance is critical for success, it has been observed by researchers that physical attractiveness of the candidates and social skills are perceived to be the essential traits for leadership abilities. While selecting employees for promotion or higher responsibilities, managers tend to give importance to the physical attributes and social skills. Chances of attractive \& beautiful people being succeeded at the workplace are more than those who do not possess the same attributes. (Dubois 2005) People believe that physically attractive people have more confidence, positive attitude and behavior. (Mahoney, 1978).

Revised Manuscript Received on December 15, 2019.

Dr. Shraddha Kulkarni, Professor, International Institute of Management Studies, Pune (Maharashtra) India.
This study aimed to investigate this phenomenon and the researcher tried to conduct qualitative \& quantitative study with industry professionals to examine if the physical attractiveness \& social skills are associated with perceived leadership abilities of the employees.

\section{LITERATURE REVIEW}

The review of literature available on the topic shows a mixture of opinions, having more inclination towards the positive correlation on this concept of people with good physical attributes and social skills are perceived to be good performers at the workplace.

A research conducted to determine behavior correlated to social status and the relative importance of physical appearance, reputation, and current behavior in the assignment of social status by peers. The result indicated that the respondents who are popular responded positively as compared to the respondents who are rejected by the peers. (Janice H. Kennedy,1990). Such research studies support the claim that social skills and physical attributes relate to creating positive impression at workplace.

As per another study, the standard of beauty has been so bounded in the culture that now it has become a natural phenomenon. Colour, facial features and gender difference can decide one's superiority over others. People with physically attractive body may not naturally hold confidence but the culture in which people grow, empowers them to grow confidence as they get approval and appreciation for physical attractiveness within which they are born. This general phenomenon also plays a great role in the employer's choice. The most attractive and well-dressed candidates tend to get promoted by the employers. (Mahajan, 2007).

Further, another research conducted to explore whether the physical appearance and social skills influence the leader behavior. This study has been conducted for college student. Canonical analysis revealed that the quality of their performance, as measured by observers' judgments and behavioral indicators, was related to their appearance and to appearance-related leadership skills. (Paul D. Chrulnik, 2010)

As stated by another researcher, physical appearance and the visual attractiveness play an important role in the personal life as well as occupational life. Studies also shows that the facial features and physical attributes leads people to think that they are better at their job and have more skills. It has been observed that people choose their leader and idealist on the basis of how attractive they appear. Masculinity and intrapersonal skill of a leader outweighs their 
other characteristics (Roberts, 2012).

In addition to this, another researcher inferred that most employers don't consciously realize that they are being biased, they are just culturally coded to believe that the good-looking people possess more capabilities than simple looking people (LoSardo, 2014).

On the contrary, another researcher conducted similar study for recruitment and selection process, claims that physical attractiveness does not play a part in selection process of individuals. Formal clothing represents a serious work attitude among candidates. Hiring solely on appearance of a candidate does occur for positions where the demand lies for such characteristics, but skill sets weigh more. Confidence of the candidate, communication skills, qualification, work-experience and relevant knowledge are important for hiring a candidate. (Usmani 2019)

With reference to the review of literature, it has been evidenced that there is a need for conducting empirical research to explore whether physical attributes and social skills are important for managers to decide about the leadership traits of the employees.

\section{METHODOLOGY}

Both qualitative and quantitative research methods were used in this research. It has used mixed methods for data collection. Exploratory and explanatory, both have been incorporated in this research. This research used primary data. Qualitative data is gathered by open-ended questionnaire (Alshenqeeti, 2014) and quantitative data has been gathered using closed-ended questionnaire.

\section{Stage 1:}

90 participants selected for first stage of the research. They were managers from multinational companies, having experience more than 10 years as leaders. With relevance to this research the participants were interviewed and asked to fill the open-ended questionnaire. The sampling technique of this research study is non-random, non-probabilistic-purposive sampling. The technique has been used because the participants of this study needed to have relevant experience in the field of people management. Data collection method was open-ended questionnaire in order to compute a better understanding of the research study. Also, keeping in consideration the accessibility of the managers, open ended questionnaires were used in the data collection. The qualitative analysis method used in this study is grounded theory. The data has been coded using manual coding that is words and phrases repetitions. The scanning of the primary data has been done for words and phrases most commonly used by respondents.

Demographics of the respondents (sample size, gender and designation)
Table I: Demographics

\begin{tabular}{|c|c|c|}
\hline & Number & $\%$ \\
\hline $\begin{array}{c}\text { No. of } \\
\text { Respondents }\end{array}$ & 90 & $100 \%$ \\
\hline Male & 60 & $67 \%$ \\
\hline Female & 30 & $33 \%$ \\
\hline \multicolumn{2}{|c|}{ Professional Backgrounds } \\
\hline Senior Managers & 85 & $94 \%$ \\
\hline Junior Managers & 05 & $06 \%$ \\
\hline
\end{tabular}

The qualitative data analysis did not show any specific difference in the respondents as far as the responses are concerned. The factors repeatedly occurred in the analysis have been grouped as below: Dressing Sense \& Grooming of the employees; Confidence; Skill set; and Gender.

Dressing Sense \& Grooming: For this factor, data suggested that it does impact on making an impression. Formal clothing represents a relatively serious work attitude which is a fundamental requirement. Professional attire \& look is an extremely important factor in case of some companies where the employees are dealing with high profile customers. In other cases, however, the balance between the appearance and other skill set has been given preference. All the respondents though agreed that proper dressing sense and well-groomed employee receives more respect as compared otherwise, but it does not have any direct relation with leadership traits.

Confidence: confidence of the employee to perform the job unanimously was the first important factor considered by all the respondents. Some of the respondents have preferred the employee who are upgrading their qualification or relevant knowledge in the field to gain leadership traits.

Skill Set: Communication and interpersonal skills are considered to be most relevant in the opinion of most of the respondents as leadership traits, however, they also have said that good communication skills blended with work ethics, technical skills and analytical skills become the most desirable combination for the effectiveness of the employees. Gender: Gender has been the least preferred factor by all the respondents; however, they have agreed on the fact that gender specification at times could be a criterion for certain profile or sectors, but overall leadership traits are not gender specific.

Stage 2:

The second stage of the research has been conducted using questionnaire survey method. Responses were collected from 270 managers from Banking Sector in Pune, Maharashtra. Convenience, non-probability sampling technique has been used to collect the data. The respondents were majorly, senior managers from across functional areas mainly from HR department. The reason for choosing these respondents as sample was that they worked closely with their team members on daily basis and these managers were perceived to be the apt respondents for evaluating the impact of physical attributes and social desirability as perceived leadership traits. The demographic characteristics of these individuals are highlighted in table II. 
Table II: Demographics

\begin{tabular}{|c|c|c|}
\hline Variables & Numbers & $\%$ \\
\hline Age & & \\
$25-40$ & 187 & $69 \%$ \\
$41-55$ & 83 & $31 \%$ \\
\hline Gender & & \\
Male & 201 & $74 \%$ \\
Female & 069 & $26 \%$ \\
\hline Qualification & & \\
Graduate & 78 & $29 \%$ \\
Postgraduate & 192 & $71 \%$ \\
\hline Level & & \\
Entry level & 135 & $50 \%$ \\
Middle Level & 117 & $43 \%$ \\
Senior Level & 18 & $7 \%$ \\
\hline
\end{tabular}

Three variables were used in this study are physical attributes, social desirability and leadership traits. Physical attributes and social desirability are both independent variables and leadership trait is a dependent variable. Table III shows the descriptive statistics of all the three variables used in this quantitative study.

Table III: Descriptive Analysis

\begin{tabular}{|c|c|c|c|c|c|c|}
\hline VARIABLE & MEAN & SD & CR & $\mathbf{1}$ & $\mathbf{2}$ & $\mathbf{3}$ \\
\hline Social Desirability & 3.2963 & $\begin{array}{c}0.497 \\
3\end{array}$ & $\begin{array}{c}0.57 \\
8\end{array}$ & $\begin{array}{c}-199^{*} \\
*\end{array}$ & $\begin{array}{c}0.07 \\
0\end{array}$ & - \\
\hline Physical Attributes & 2.9781 & 0.765 & $\begin{array}{c}0.92 \\
1\end{array}$ & - & - & - \\
\hline Leadership Traits & 3.9432 & $\begin{array}{c}0.652 \\
1\end{array}$ & $\begin{array}{c}0.75 \\
3\end{array}$ & -0.054 & - & - \\
\hline
\end{tabular}

$\mathrm{N}=194, \mathrm{p}<0.05^{*}, \mathrm{p}<0.01^{* *}$

A short version of 13 items, social desirability scale was used from Crowne, and Marlowe, (1960). When exploratory factor analysis has been conducted to verify an underlying structure of the variable. Physical attributes \& Social desirability found to have coefficients less than 0.5 , therefore certain items were removed from 13 items; namely, SD1, SD2, SD3, SD4, SD5, SD7, SD8, SD9 and SD13. Only items SD6, SD10, SD11, and SD12 were retained in the study as they explained $47.49 \%$ variance.

Principal component analysis has been used for developing the scale for "physical attraction" as it was not available. 2 items were created to measure the impact of physical attractiveness on perceived leadership using Likert scale of 1 to 5 where 1 refers to "Do not agree", 2 refers to "Agree a little", 3 refers to "Agree moderately", 4 refers to "Agree to larger extend", and 5 refers to "Totally Agree". Table IV indicates the analysis outcomes.

Table IV: Principal Component Analysis

\begin{tabular}{|l|l|}
\hline $\begin{array}{l}\text { Physically Attributes of the } \\
\text { Candidates as Leadership Traits }\end{array}$ & $\begin{array}{l}\text { Component } \\
\text { Extraction }\end{array}$ \\
\hline $\begin{array}{l}\text { Physical attributes of the employees s } \\
\text { create a positive impact }\end{array}$ & .843 \\
\hline $\begin{array}{l}\text { Physical attributes of the employees } \\
\text { affect the perceived leadership abilities }\end{array}$ & .815 \\
\hline
\end{tabular}

Perceived leadership traits of managers were measured using the Multifactor Leadership Questionnaire (MLQ)-1 of Bass (1985), subsequently modified by Kim and Lee (2001). The 27-item MLQ-1 used a 5-point Likert scale (1 = not at all, 5 = very much so) to assess each of the three subfactors: charisma, individual consideration, and intellectual stimulation. In order to evaluate the reliability of Multifactor Leadership Questionnaire, following approach has been considered.

Internal consistency was calculated for each of the MLQ-5X subscales. As a standard, Cronbach's Alpha was calculated for each subscale of the MLQ-5X (Cortina, 1993). Table V presents the internal consistencies of the MLQ-5X scales as indicated by Cronbach's Alpha are good.

Table V: Reliability Test Result

\begin{tabular}{|c|c|}
\hline Items of MLQ-5X & Reliability \\
\hline Charisma & 0.91 \\
\hline Individual Consideration & 0.89 \\
\hline Intellectual Stimulation & 0.87 \\
\hline
\end{tabular}

Table VI presents the mean, standard deviation and internal consistency estimates for the MLQ-5X scale. The results of this indicated that the scale is reliable and can be useful for the purpose of the present study.

Table VI: Means, standard deviations, and internal consistency estimates

\begin{tabular}{|c|c|c|c|}
\hline Items of MLQ-5X & $\mathrm{M}$ & $\mathrm{SD}$ & $\mathrm{A}$ \\
\hline Charisma & 3.14 & 0.79 & 0.77 \\
\hline $\begin{array}{c}\text { Individual } \\
\text { Consideration }\end{array}$ & 3.22 & 0.89 & 0.84 \\
\hline $\begin{array}{c}\text { Intellectual } \\
\text { Stimulation }\end{array}$ & 3.29 & 0.81 & 0.76 \\
\hline
\end{tabular}

To evaluate the relationship between two independent and one dependent variable, two hypotheses have been designed and tested by using correlation and regression matrix. Two hypotheses were designed as follows;

H1: Physical attributes has a significant effect on perceived leadership traits of the employees.

H2: Social desirability has a significant effect on perceived leadership traits of the employees.

Hypothesis Testing

H1: Physical attributes has a significant effect on perceived leadership traits of the employees.

H0: Physical attributes has no significant effect on perceived leadership traits of the employees.

The null hypothesis has been tested using Correlation and Regression Matrix. Summary statistics, correlations and results from the regression analysis of physical attributes and perceived leadership are as follows: 
Table VII: Correlation \& Regression Matrix

\begin{tabular}{|c|c|c|c|c|c|}
\hline $\begin{array}{c}\text { Variable } \\
\text { mean std } \\
\text { correlation } \\
\text { with }\end{array}$ & mean & std & $\begin{array}{c}\text { correlation } \\
\text { with PA }\end{array}$ & \multicolumn{2}{|c|}{$\begin{array}{c}\text { Multiple } \\
\text { regression } \\
\text { weights }\end{array}$} \\
\hline PA2 & 578.0 & 82 & $-185^{*}$ & $-0066^{*}$ & -254 \\
\hline PA3 & 559.2 & 62 & $-229 *$ & $-0042 *$ & -055 \\
\hline PA4 & 419.3 & 61 & $-135 *$ & $-0034^{*}$ & -123 \\
\hline
\end{tabular}

It has been found that there is no relationship between physical attraction and perceived leadership traits. The regression analysis indicated that $p$-value of physical attraction and leadership traits $\mathrm{p}>0.05$ (i.e. $-185,-229,-135$ ) have been negative, so the null hypothesis is true.

H2: Social desirability has a significant effect on perceived leadership traits of the employees.

H0: Social desirability has no significant effect on perceived leadership traits of the employees.

The null hypothesis has been tested using Correlation and Regression Matrix. Summary statistics, correlations and results from the regression analysis of social desirability and perceived leadership are as follows:

Table VIII: Correlation \& Regression Matrix

\begin{tabular}{|l|l|l|l|l|l|}
\hline $\begin{array}{l}\text { Variable } \\
\text { mean std } \\
\text { correlation } \\
\text { with }\end{array}$ & mean & std & & $\begin{array}{l}\text { lorrelation } \\
\text { with SD }\end{array}$ & \multicolumn{2}{l|}{$\begin{array}{l}\text { Multiple } \\
\text { regression } \\
\text { weights } \\
\text { b }\end{array}$} \\
\hline SD6 & 578.0 & 78 & $-234^{*}$ & $-0065^{*}$ & -178 \\
\hline SD11 & 559.2 & 87 & $-189 *$ & $-0023^{*}$ & -156 \\
\hline SD12 & 419.3 & 69 & $-222^{*}$ & $-0067 *$ & -009 \\
\hline
\end{tabular}

$* \mathrm{p}<.05 * * \mathrm{p}<.01 * * * \mathrm{p}$

It has been found that there is no relationship between social desirability and perceived leadership traits. The regression analysis indicated that p-value of social desirability and leadership traits was also found to be insignificant and negative with $\mathrm{p}>0.05$ (i.e. $-234,-189,-222$ ). So, the null hypothesis is true.

\section{FINDINGS \& CONCLUSION}

After carefully evaluating the outcomes of the applied methodology, the author has concluded that the hypotheses of the present research are proved to be rejected. It has been found that there is no relationship between physical attraction and perceived leadership traits with $\mathrm{p}>0.05$ (i.e. $-185,-229$, -135) and social desirability and perceived leadership traits being $\mathrm{p}>0.05$ (i.e. -234, -189, -222). Thus, both hypotheses have been rejected. The results are consistent with the first study that physical attraction and social desirability do not have relationship with perceived leadership traits. With the help of the results of the present study, it can be concluded that perceived leadership traits for being successful in the job roles have less to do with the physical attributes and social desirability of an individual. According to the respondents in the present study, communication skills, technical expertise and interpersonal skills are more important for an individual to become a successful leader.

This research will be helpful for the HR professional while drafting the job profile for leadership positions. This study will also serve as a reference point for HR managers while designing the training needs for leadership development.

\section{LIMITATIONS \& FUTURE SCOPE}

This research is limited to the sample size of 90 in the first stage and 270 respondents in the second stage. Thus, it may be possible that the results will vary if the sample size increases. Another limitation of the study is that, the profile of the sample respondents varies in both the stages, thus it can be possible that if the sample profile is constant in both the stages, the outcomes may vary. Further studies can be conducted for certain sectors/companies specifically working with service industries where physical attributes and social desirability could be an essential factor for leaders.

\section{REFERENCES}

1. Cotter, L. (2011), "Self-Perceived Attractiveness and Its Influence on the Halo Effect and the Similar-to Me Effect"

2. Crowne, D. P., \& Marlowe, D. (1960), "A new scale of social desirability independent of Psychopathology", Journal of consulting psychology, 24(4), 349.

3. Dion, K. K., Berscheid, E., \&Walster, E. (1972), "what is beautiful is what is good", Journal of Personality and Social Psychology, 24, 285-29.

4. Dubois, N. (2005), "Social judgment norms and value: Anchoring in utility and anchoring to Desirability", International Review of Social Psychology, 18, 43-79.

5. Dubois, N., \& Beauvois, J. L. (2001), "Désirabilité et utilité: Deux composantes de la valeur des personnes dans l'évaluation sociale" L'orientation Scolaire et Professionnelle, (30/3).

6. Hamermesh, J. E., \& Biddle. (1994), "Beauty and the Labor Market. American Economic Review", 1174-1194.

7. Hanan. M. (2017), "Impact of human resource management on organizational performance within firms in Saudi Arabia”, International Journal of Advanced Research. 1-19

8. Heilman, M. E., \& Stopeck, M. H. (1985), "Attractiveness and corporate success: Different causal attributions for males and females", Journal of Applied Psychology, 70 (2), 379.

9. Janice H. Kennedy, Determinants of peer social status: Contributions of physical appearance, reputation, and behavior, pp 233-244, Journal of Youth and Adolescence, June 1990, Volume 19, Issue 3

10. Mahajan, R. (2007), "The Naked Truth: Appearance Discrimination, Employment, and the Law. Asian American Law Journal", 165-203.

11. Mahoney, S. D. (1978), "The effects of physical appearance and behavior. A Dissertation psychology", 417-422.

12. Paul D. Cherulnik (2010), Physical Appearance, Social Skill, and Performance as a Leadership Candidate, Pages 287-295, Journal: Basic and Applied Social Psychology, Volume 16, 07 Jun 2010- Issue 3

13. Roberts, S. C. (2012), "Evolution, Appearance, and Occupational Success. Evolutionary Psychology", 782-801.

14. Sierminska, E. (2015), "Does it pay to be beautiful?", Germany: LISER, Luxembourg, and DIW Berlin and IZA.

15. Stefanie, K., Johnson, K. E., Podratz, R. L., \& Dipboye, E. G. (2010), "Physical Attractiveness Biases in Ratings of Employment Suitability: Tracking Down the "Beauty is Beastly" Effect", The Journal of Social Psychology, 301-318.

16. Usmani (2018), Recruitment and Selection Process at Workplace: A Qualitative, Quantitative and Experimental Perspective of Physical Attractiveness and Social Desirability; Review of Integrative Business and Economics Research, Vol. 9, Issue 2

17. Yong-Sook (2014), Path Analysis of Empowerment and Work Effectiveness among Staff Nurses, https://doi.org/10.1016/j.anr.2014.02.00 


\section{AUTHORS PROFILE}

Qualification: Ph.D. (Leadership Development), MBA-HR, PGDCA

Experience: Academic \& Research: 12 Years in Teaching; Corporate Trainer \& Consultant: 7 Years

Training Profile: Grooming \& Personal Effectiveness Expert, Managerial Effectiveness, HR Processes and Global Psychometric Assessor

Subjects Expert: Organizational Behaviour, Business Communication, HRM, Training \& Development, Talent Management, Strategic HRM, Emotional Intelligence, Recruitment \& Selection, Competency Mapping \& Leadership Development etc. Research Profile: 25 Papers published in National \& International Journals of repute, including Scopus Indexed Journal and Journals with high Impact Factors in the area of Leadership, Emotional Intelligence \& HRM

Achievements: Best Faculty Award 2018, Best Presenter Award by IIM-A, Invited as Guest/Session Chair for International Conferences at Goa, Japan, Dubai, Bangkok and South Korea

International Faculty at James Cook University, Singapore

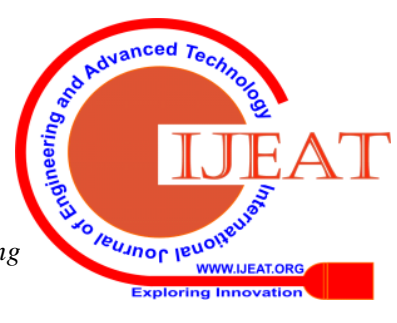

